\title{
Foeniculum vulgare as Valuable Plant in Management of Women's Health
}

\author{
Mohaddese Mahboubi \\ Medicinal Plants Research Department, Research and Development, TabibDaru Pharmaceutical Company, Kashan, Iran
}

This review paper evaluates use of Foeniculum vulgare extracts as a popular female plant in management of different ailments of women. Information in this paper was gathered from accessible sources (PubMed, Science Direct, Springer, Wiley, and Google), and traditional books (Persian or English modern traditional books), unpublished data (R\&D reports, thesis and dissertation) by keywords based on the words F. vulgare or fennel and women. Efficacy of oral fennel oil in management of dysmenorrhea, premenstrual syndrome, amenorrhea, menopause, lactation, and polycystic ovary syndrome were confirmed according to results of clinical studies. Results of clinical efficacy of fennel oil on menstrual bleeding is complicated, but results of one meta-analysis study revealed that fennel oil significantly increased means of bleeding in the first menstrual periodic cycle $(P=0.001)$, while fennel oil had no significant effect on bleeding in the second menstrual cycle $(P=0.67)$. Topical and vaginal fennel extract (5\%) exhibited good efficacy in treatment of sexual function, vaginal atrophy, and hirsutism. Fennel had no effect on bone density, or body mass index of menopause women. Results of clinical studies introduce fennel as a valuable medicinal plant in management of women's ailments, but understanding the mechanism of action could be the subject of future studies.

(J Menopausal Med 2019;25:1-14)

Key Words: Fennel · Foeniculum vulgare · Women · Phytoestrogens · Lethal dose 50

\section{Introduction}

Foeniculum vulgare as the member of Apiaceae family with common name of fennel is well-known flowering medicinal plants in traditional and modern medicines. In Iranian Traditional Medicine, fennel was known as "Razaianeh", "Razianaj", "Badian", and "Marsoun". According to Iranian traditional believes, fennel with hot and dry nature is used as galactagogue, diuretic, emmenagogue, mucolytic and lithontriptic agents. Fennel is effective remedy for visual acuity, cataract, catarrh, stomachache, chronic diarrhea, nausea, vomiting, chronic fever, kidney stones, internal obstructions, and urinary diseases. Topical application of fennel fruit powder on abdomen is good treatment for infantile colic. Constipation is caused after oral administration of fennel fruits and roots. ${ }^{14}$ Although, there are some review articles on fennel ${ }^{5-7}$ in literatures that summarized its biological or pharmacological effects, but there is no review article, which evaluated the use of fennel in management of women's ailments. The subject of this review article was to provide a concise conclusion on efficacy of fennel in women health.

\section{Methods}

The manuscript was prepared by searching in electronic

Received: July 29, 2018 Revised: September 3, 2018 Accepted: September 23, 2018

Address for Correspondence: Mohaddese Mahboubi, Medicinal Plants Research Department, Research and Development, TabibDaru

Pharmaceutical Company, Kashan 8715115815, Iran

Tel: +98-31-55541000, Fax: +98-31-55541000, E-mail: mahboubi1357@yahoo.com

ORCID: https://orcid.org/0000-0003-4732-7302 
accessible resources (PubMed, Wiley, Springer, Google Scholar, Science Direct, SID, and Magiran) or thesis, traditional and modern books by key words of fennel, Foeniculum vulgare, plus women diseases, clinical trial. The results were categorized on the base of disease and the results of investigations were discussed.

\section{Fennel in management of premenstrual syndrome (PMS)}

PMS is prevalent ailment among women. They experience wide variety of physical disturbances and emotional symptoms such as mood swings, food carving, tender breasts, depression, irritability, headache and fatigue, 5 to 11 days before menstrual periods. Sex hormones, ovarian steroids, and serotonin levels are involved in PMS symptoms. Fennel as important medicinal plant with long history in management of PMS symptoms has been the subject of four clinical trials in women with PMS symptoms (Table 1). In the first clinical trial, the efficacy of fennel oil oral drop $(\mathrm{n}=$ $36)$ was compared to mefenamic acid $(n=36)$ or placebo ( $n$ = 32) in patients with PMS. The patients received 20 to 30 drops of fennel oil oral drop or placebo every 4 to 8 hours, or mefenamic acid capsule (250 mg) every 6 hours from the beginning of pain feeling during two menstrual cycles. After the first cycle of interventions, there was no significant difference in menstrual clinical symptoms (vomiting, diarrhea, headache, fatigue, and lethargy) among three groups, while in second menstrual cycles, intervention by fennel oil or mefenamic acid significantly improved the menstrual clinical symptoms compared to placebo $(P<0.05)^{8}$ In second randomized placebo clinical study on efficacy of fennel oil oral drop on 60 students with PMS was compared with placebo. The patients randomly divided in two groups $(\mathrm{n}=30)$, who received daily 60 drops of fennel oil $(2 \% ; \mathrm{n}=28)$ or placebo ( $n=27)$ in three divided doses, 3 days before and after of menstrual period for 2 periodic cycles. The daily record of PMS severity symptoms (anxiety, depression, excitement, and physical symptoms) and adverse effects related to treatment on the score of zero to 4 were determined for 2 menstrual cycles before and after treatments. At baseline, there was no significant difference between two groups in regard of demographic, PMS clinical symptoms, menstrual bleeding level, and body mass index (BMI). Fennel oil oral drop significantly reduced the severity of anxiety, depression and

Table 1. Efficacy of fennel oil oral drop (2\%) in management of premenstrual syndrome (PMS)

\begin{tabular}{|c|c|c|c|c|c|}
\hline Study & Intervention & Control & How to use & Results & $\begin{array}{l}\text { Adverse } \\
\text { effects }\end{array}$ \\
\hline $\begin{array}{l}\text { Nazarpour } \\
\text { and } \\
\text { Azimi }^{8}\end{array}$ & $\begin{array}{l}\text { Fennel oil } \\
\text { oral drop } \\
(n=36)\end{array}$ & $\begin{array}{l}\text { Mefenamic acid }(n=36) \\
\text { or placebo }(n=32)\end{array}$ & $\begin{array}{l}20-30 \text { drops of fennel oil oral drop } \\
\text { or placebo every } 4-8 \mathrm{~h} \text {, or } \\
\text { mefenamic acid capsule } \\
(250 \mathrm{mg}) \text { every } 6 \mathrm{~h} \text { from the } \\
\text { beginning of pain during } \\
\text { two menstrual cycles }\end{array}$ & $\begin{array}{l}\text { No significant difference in } \\
\text { menstrual clinical symptoms } \\
\text { after the first cycle } \\
\text { Improvement in menstrual } \\
\text { clinical symptoms after } \\
\text { second cycle }\end{array}$ & - \\
\hline $\begin{array}{l}\text { Delaram } \\
\text { and } \\
\text { Jafari }^{9}\end{array}$ & $\begin{array}{l}\text { Fennel oil } \\
(\mathrm{n}=28)\end{array}$ & Placebo $(n=27)$ & $\begin{array}{l}20 \text { drops of fennel oil oral drop } \\
(2 \%) \text { in three divided doses, } \\
\text { three days before and after of } \\
\text { menstruation for } \\
\text { two periodic cycles }\end{array}$ & $\begin{array}{l}\downarrow \text { Severity of anxiety, } \\
\text { depression and } \\
\text { total clinical symptoms } \\
\text { No effect on excitement, } \\
\text { fluid accumulation and } \\
\text { physical signs of PMS }(P>0.05)\end{array}$ & $\begin{array}{l}\text { No } \\
\text { adverse } \\
\text { effects }\end{array}$ \\
\hline Omidali $^{10}$ & $\begin{array}{l}\text { Fennel oil } \\
(\mathrm{n}=10)\end{array}$ & $\begin{array}{l}\text { Pilates exercises } \\
\text { plus fennel }(n=10) \\
\text { Pilates exercises }(n=10) \\
\text { Control }(n=10)\end{array}$ & $\begin{array}{l}30 \text { drops of fennel oil } \\
\text { oral drops ( } 2 \% \text { ) every } 12 \mathrm{~h} \\
\text { for one month }\end{array}$ & $\begin{array}{l}\text { No effect on mood and } \\
\text { behavioral symptoms }(P=0.306) \\
\text { Higher effect on } \\
\text { physical symptoms }\end{array}$ & - \\
\hline $\begin{array}{l}\text { Pazoki } \\
\text { et al. }^{11}\end{array}$ & Fennel oil & $\begin{array}{l}\text { Aerobic exercise, } \\
\text { fennel plus } \\
\text { aerobic exercise, } \\
\text { and control groups }\end{array}$ & $\begin{array}{l}20 \text { drops of fennel oil oral drop } \\
(2 \%) \text { in three divided doses, } \\
\text { three days before and after of } \\
\text { menstruation for } \\
\text { two periodic cycles }\end{array}$ & $\begin{array}{l}\downarrow \text { PMS severity } \downarrow \text { anxiety } \\
\text { and depression }\end{array}$ & \\
\hline
\end{tabular}


total clinical PMS symptoms compared to placebo group. The adverse effects related to treatment were not significant among two groups. Fennel oil had no effect on excitement, fluid accumulation and physical symptoms of PMS $(P>0.05){ }^{9}$ The results of two above clinical studies confirmed the therapeutic effects of fennel oil on PMS symptoms comparable to mefenamic acid. Fennel oil decreased the pain, anxiety, depression as clinical symptoms of PMS.

In two other randomized clinical studies, ${ }^{10,11}$ the effects of fennel oil along with exercise was evaluated on clinical symptoms of PMS. In first clinical study, 40 women with PMS were randomly divided in four groups of fennel plus Pilates exercise, Pilates, fennel or control groups $(n=10)$. Pilates exercises were performed three times in a week for 4 weeks. The patients in fennel group received 30 drops of fennel oil oral drop (2\%) every 12 hours for one month. A significant improvement was observed in patient's mood $(P$ $=0.001)$, physical symptoms $(P=0.0001)$, and quality of life $(P=0.0001)$ in fennel plus Pilates exercise group compared before treatment. No significant difference in PMS clinical symptoms was recorded in placebo group. Mood and behavioral symptoms were no affected in fennel oil compared to before intervention $(P=0.306){ }^{10}$ The last study showed that fennel oil oral drop improved the efficacy of Pilates on mood and behavioral symptoms of PMS compared with fennel oil alone and placebo treatments. Contrary to the results of study of Delaram and Jafari ${ }^{9}$ in 2011, fennel oil had no effects on mood and behavioral symptoms of PMS women. In other randomized clinical trial, 48 students (16-18 years old) with PMS symptoms, who were divided into four equal groups of fennel oil, aerobic exercise, fennel oil plus aerobic exercise and placebo groups. They filled the daily record of severity of problem questionnaire (DRSP-Q) before intervention, after the first and second menstrual cycles. The patients received 30 drops of fennel oil oral drop (2\%) every 8 hours, 3 days before and after menstrual cycle. Ten minute warm-up, fast exercise in limb and trunk for 40 minutes and then 10 minutes cool down was the aerobic exercise program. Aerobic exercise, fennel oil or fennel oil along with aerobic exercise groups significantly reduced PMS severity after first and second menstrual cycles, compared with placebo group. There was no significant difference in average of PMS symptoms among three groups after first and second menstrual cycles. The anxiety and depression, influenced effectively after intervention with fennel plus exercise than that of fennel or exercise alone. ${ }^{11}$ The results of above clinical studies confirmed the effectiveness of fennel oil alone or in combination with exercise in reduction of PMS severity symptoms, anxiety and depression. The effectiveness of fennel oil on behavioral symptoms is related to its estrogenic compounds, which makes it as suitable treatment for estrogen deficits disorders. Estrogens are effective hormones in anxiety through the intervention of gamma-aminobutyric acid (GABA) receptors. The intervention of estrogen or GABA receptors in presence of fennel oil was confirmed in adult Wistar rats in comparison with tamoxifen, pirotoxin by elevated plus maze. Blocking the GABA receptor by pirotoxin, inhibits the anti-anxiety effects of fennel oil, which implies the involvement of GABA receptors in antianxiety effects of fennel oil. Blocking the estrogen receptors by tamoxifen inhibited the anti-anxiety effects of fennel oil, without any effects on motor activity. ${ }^{12}$ Fennel aerial parts essential oil in low doses of 50 or $100 \mathrm{mg} / \mathrm{kg}$ has anxiolytic effects comparable to diazepam, while in higher doses (200 $\mathrm{mg} / \mathrm{kg}$ ) show sedative effects. ${ }^{13}$ Therefore, the estrogenic compounds in fennel oil along with analgesic effects reduce the behavioral and physical symptoms in patients with PMS.

\section{Fennel and its effects on menorrhagia}

Menorrhagia is defined as abnormally heavy or prolonged bleeding during menstruation. It is believed that fennel oil accelerate the bleeding from uterine in short intervals. This chapter answers this question "does fennel increase the bleeding during the menstruation or no?"

In one clinical trial on single students with primary dysmenorrhea, 20 to 30 drops of fennel oil oral drop $(n=36)$, every 4 to 8 hours from the beginning of pain feeling during two periodic cycles, reduced the menstrual bleeding in three days of treatments. ${ }^{8}$ In other randomized double blind study, on 60 patients with moderate and severe primary dysmenorrhea, 0.3 to $1 \mathrm{~mL}$ fennel oil (1\% and $2 \%$ ) significantly increased the total bleeding score during menstruation compared with placebo group $(P<0.01){ }^{14}$

Consumption of fennel fruit ethanol extract capsule (230 $\mathrm{mg}$ ) in the first three days of menstrual period of two menstrual cycles had no effect on menstrual period or severity of 
bleeding $(P>0.05){ }^{15}$ One-hundred drops of fennel oral drop (2\%) in treatment of primary dysmenorrhea of 60 students during two menstrual cycles had no significant effect on bleeding severity $(P=0.89){ }^{16}$ Seventy-five drops of fennel oral drop (2\%) had no effects on bleeding severity and the number of consumed pad, bleeding scores compared with control group. ${ }^{17}$ A significant reduction in duration of menstrual period without any effect on menstrual bleeding after two and three month's consumption of fennel soft capsule (daily $180 \mathrm{mg}$ ) was observed. The patients received soft capsules 3 days before menstruation till the 5th day of 3 menstrual cycles. ${ }^{18}$ The results of clinical studies on administration of fennel oil on menstrual bleeding are complicated, but a results of systematic review showed fennel oil significantly increased the means of menstrual bleeding in the first cycle of treatment $(P=0.001)$, while it had no significant effect on menstrual bleeding in second cycles of treatments compared to control group $(P=0.67){ }^{19}$

\section{Fennel and its potency in dysmenorrhea}

Dysmenorrhea as most prevalent gynecological disease is known as painful menstrual cramps during menstruation. The periodic cramps in lower abdomen start from the beginning of menstruation and last for three days. A massive clinical trials were performed on the efficacy of fennel on primary dysmenorrhea $(\mathrm{n}=13)$ (Table 2$)$.

A cohort clinical study on the efficacy of 25 drops of fennel oil oral drop $(2 \%)$ every 4 hours $(n=24)$ in comparison with mefenamic acid (250 mg) capsule every 6 hours $(\mathrm{n}=$ 30) on women suffering from primary dysmenorrhea was performed. Fennel oil or mefenamic acid significantly reduced the menstrual pain compared with control group $(P<$ 0.001). The initiation time for effectiveness of fennel oil or mefenamic acid was not significance $(P=0.57)$. The effects of mefenamic acid on dysmenorrheal symptoms in second and third days of menstruation significantly were higher than fennel oil $(P<0.05)$. There were no adverse effects for mefenamic acid, while five drop-out due to the bad odor and taste of fennel oil and one increase in menstrual fluid was reported for fennel oil oral drop. ${ }^{20}$ The efficacy of fennel on five menstrual cycles of 60 dysmenorrheal patients compared control showed that fennel was effective on severity of pelvic or abdominal pain $(P<0.001)$, lethargy $(P<0.0001)$, and depression $(P<0.05)$, in comparison with control group. Fennel oil non-significantly improved the other clinical symptoms of PMS (breast pain, vomiting, bloating, diarrhea, inflammation, appetite, muscle or arthritis pain, anxiety), compared to control group. ${ }^{21}$ Thirty drops of fennel oil oral drop or mefenamic acid capsule (250 mg) every 6 hours from the beginning of menstruation during two menstrual cycles showed that the pain score, activity and need to rest significantly improved compared to before intervention. There was no significant difference between two groups after treatments. ${ }^{22}$ Consumption of daily $46 \mathrm{mg}$ fennel extract capsules ( $\mathrm{n}=5,2$ capsules in the morning, 2 in the noon and 1 in the night) during the first three days of two periodic cycles ( $n=46$ ) of women with primary dysmenorrhea compared to placebo capsule $(n=44)$ non-significantly reduced the analgesic consumption. The severity of pain, the number of patients without pain, and lethargy significantly reduced in fennel group. No adverse effects reported after intervention with fennel extract. ${ }^{23}$ In other clinical study, 20 to 30 drops of fennel oil oral drop or placebo every 4 to 8 hours, or mefenamic acid capsule (250 mg) every 6 hours from the beginning of pain during two menstrual significantly reduced pain severity, three days after interventions compared with placebo group. Although, the mean of pain severity in fennel oil was lower than mefenamic acid, but the difference was not significant. Fennel oil was more effective than mefenamic acid in reduction of pain. ${ }^{8}$ The fennel oil oral drop (1\% and $2 \%$ ) of 0.3 to $1 \mathrm{~mL}$ significantly reduced the severity of pain and means of dysmenorrhea severity in dysmenorrheal patients $(P<0.05)$, without any significant effect on fatigue, dizziness, diarrhea, headache, faint, and mood changes. The use of other medications to relief of symptoms were $66.7 \%$, $41.8 \%$ and $39.9 \%$ in placebo group, fennel oil (1\% and $2 \%$ ), respectively. Nausea was reported in one subject of mefenamic acid group. ${ }^{14}$ The means of dysmenorrhea severity after interventions with 20 drops of fennel oil (2\%) or placebo every 8 hours, 3 days before and after of menstruation for 2 periodic cycles were $10.67 \pm 6.07$ and $16.11 \pm 6.35$, respectively. After second intervention, the corresponding values were $9.29 \pm 6.18$ and $15.94 \pm 7.43$, respectively $(P<$ 0.05). ${ }^{24}$ Regardless the superiority of fennel oil than that of mefenamic acid and placebo in dysmenorrhea, administration of $46 \mathrm{mg}$ fennel oil every 6 hours $(\mathrm{n}=22)$ in compari- 


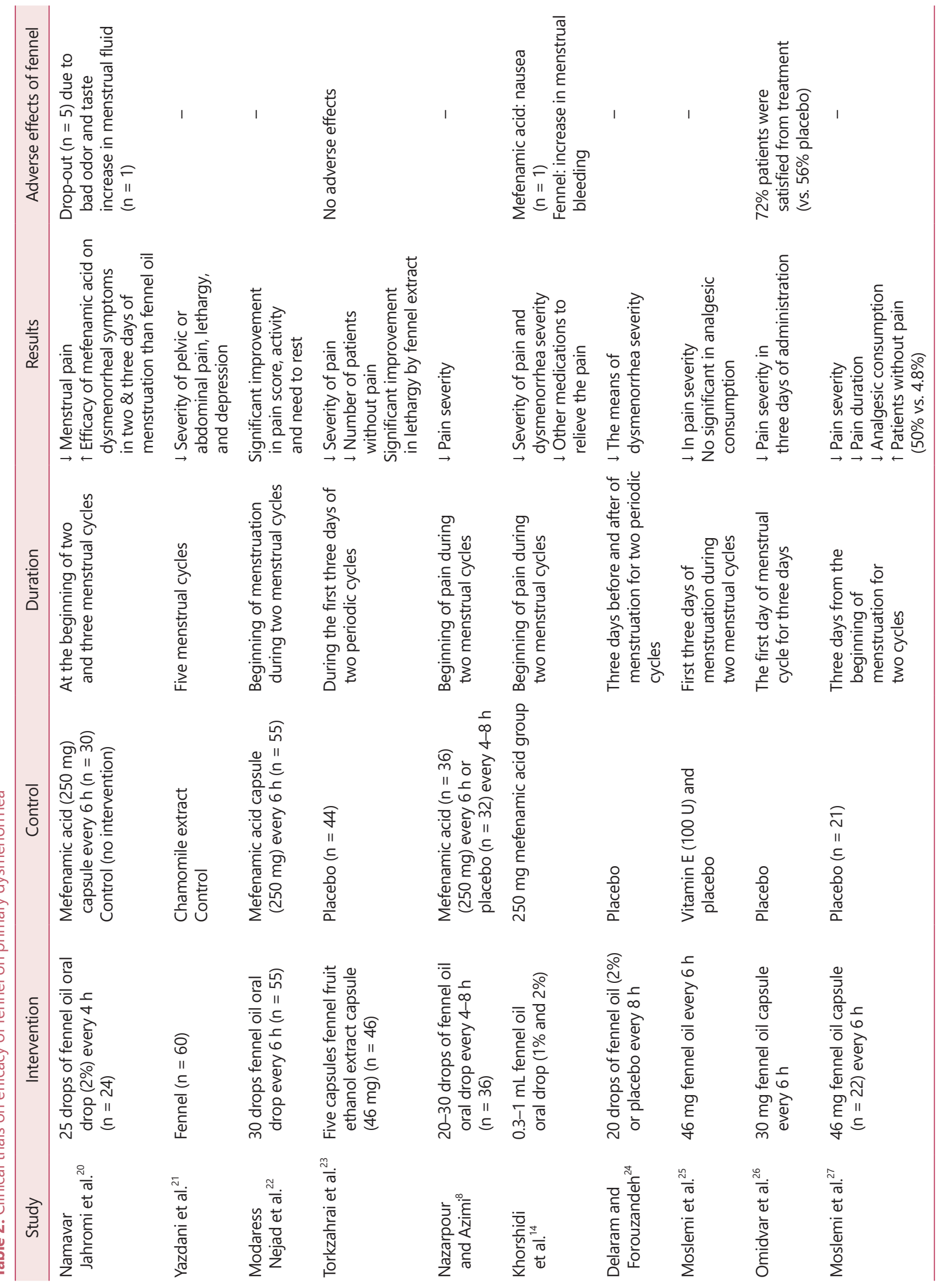




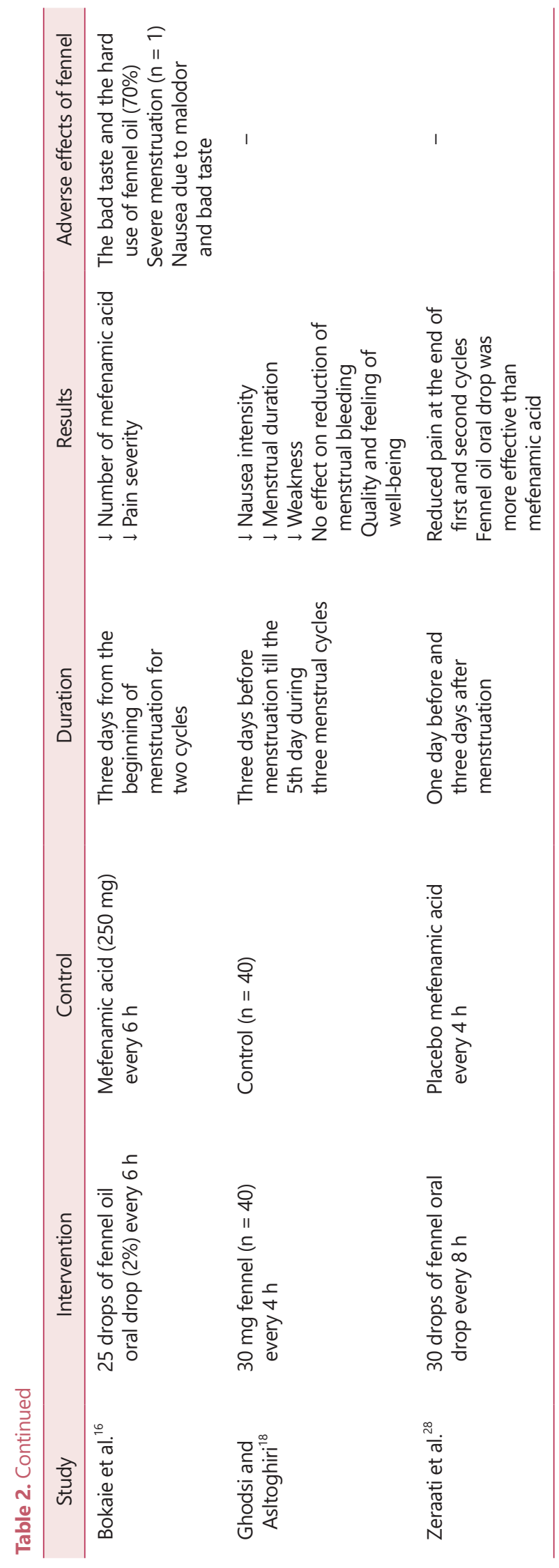

son with vitamin $\mathrm{E}(100 \mathrm{U} ; \mathrm{n}=20)$ and placebo $(\mathrm{n}=21)$ for first three days of menstruation during 2 menstrual cycles showed that the average days with pain were $1.8 \pm 0.8,2.6$ \pm 1.0 , and $2.1 \pm 0.8$ for fennel oil, vitamin $\mathrm{E}$ and placebo, respectively $(P=0.03)$. In second cycle, the corresponding days with pain were $1.5 \pm 0.8,2.0 \pm 0.9$, and $1.9 \pm 0.9$, respectively. The reduction in pain after intervention was significant among three groups and this reduction was more significant in fennel group $(P=0.019)$. The means of pain severity significantly reduced after first and second intervention by vitamin $\mathrm{E}$, or fennel oil $(P=0.02$ and $<0.001)$. Fennel oil was more effective than placebo and vitamin $\mathrm{E}$ in reduction of pain and dysmenorrhea ${ }^{25}$ In one clinical study on 50 virgin girls, consumption of $30 \mathrm{mg}$ fennel oil capsule, four times in a day from the first day of menstrual cycle for three days significantly reduced pain severity in three days of intervention, compared with placebo group $(P<0.01)$. Patients of $72 \%$ were satisfied from fennel oil vs. $56 \%$ in placebo group. ${ }^{26}$ In other study, $46 \mathrm{mg}$ fennel oil capsule ( $\mathrm{n}$ = 22) every 6 hours for three days from the beginning of menstruation for 2 cycles reduced the average of pain from $0.93 \pm 2.73$ to $0.66 \pm 2.18$ and $0.66 \pm 1.59$ after one and second month intervention $(P<0.006)$. The patients without pain, pain duration and analgesic consumption significantly improved in fennel compared with placebo group. ${ }^{27}$ Twentyfive drops of fennel oil oral drop (2\%) in comparison with mefenamic acid $(250 \mathrm{mg})$ in primary dysmenorrhea had no significant effect on pain relief $(P=0.577)$, bleeding severity $(P=0.89)$, pain intensity $(P=0.89)$ compared to control group. The number of mefenamic acid was significantly lower in fennel group (4 cases) than control group. Bad taste of fennel oil (70\%) and severe menstruation (1 case) were the adverse effects of fennel oil drop. ${ }^{16}$ Administration of fennel oil (30 mg) soft capsule, every 4 hours, 3 days before menstruation till the 5th day, reduced significantly nausea intensity, menstrual duration and weakness without any effects on menstrual bleeding after 3 months of intervention by fennel group, compared with control group ( $\mathrm{n}=$ 40). Quality and feelings of well-being significantly improved after 1 and 3 months of fennel oil consumption, compared with placebo group. ${ }^{18}$

Thirty drops of fennel oral drop or placebo every 8 hours, or mefenamic acid capsule (250 mg) every 4 hours one day 
before and 3 days after menstruation, reduced pain at the end of first and second cycles, compared to placebo group or before intervention. Fennel oil oral drop was more effective than mefenamic acid on dysmenorrheal pain. ${ }^{28}$ According to the results of clinical studies, fennel oil reduces the symptoms of dysmenorrhea, comparable to nonsteroidal antiinflammatory drugs (NSAIDs) and is more effective than vitamin E. The results of one clinical study show no superiority of fennel than placebo in clinical symptoms of dysmenorrhea. Therefore, fennel oil as oral drop or soft capsule can be used for management of pain during dysmenorrheal periods instead of chemical NSAIDs. The bad taste and odor of fennel oil is its complication.

\section{Mechanism of action for fennel in management of dysmenorrhea}

The main reason for primary dysmenorrhea is ectopic uterine motility, which is associated with pain. Short term therapy by NSAIDs (diclofenac, ibuprofen) is highly recommended to relieve the pain in dysmenorrhea. NSAIDs by inhibition of prostaglandins synthesis in blood reduce the pain during primary dysmenorrhea. The smooth muscle relaxant agents are also used during the dysmenorrhea. Fennel oil has inhibitory effect on contractile related to oxytocin and prostaglandins. Although, the main reason for primary dysmenorrhea is unknown, but the acceptable theory for primary dysmenorrhea is in over production of endometrial prostaglandins. Ovarian steroids, pituitary prostaglandins and cervical obstruction are the main reasons for uterine hyperactivity. Prostaglandins constrict the uterine smooth muscle and cause the colic pains; therefore, a drug with antispasmodic action is effective treatment for reducing the pain. ${ }^{29}$ Fennel oil inhibited the response of uterine to oxytocin and prostaglandin $\mathrm{E}_{2}$ by reducing its contraction frequency and intensity. The mechanism of action of fennel oil is similar to diclofenac, which has direct effect on uterine smooth muscle and central system. ${ }^{30}$ Anethole as the main components of fennel oil has the similar structure to dopamine, which binds to dopamine receptors and decreases the pain. The spasmolytic action of fennel oil is mediated by inhibition of acetyl choline and histamine induced contractile. $^{25}$ The antinociceptive effects of fennel aqueous extract on visceral pain were comparable to indomethacin in male albino NMRI mice $(P<0.001)$. The antinociceptive effects of fennel aqueous extract was not inhibited by naloxone, while it attenuated by chlorpheniramine and cimetidine $\left(\mathrm{H}_{1}\right.$ and $\mathrm{H}_{2}$ blockers). Therefore, the antinociceptive effects of fennel aqueous extract are partially mediated by histamines $\mathrm{H}_{1}, \mathrm{H}_{2}$ receptors. $^{31}$

\section{Fennel and its effects on menopause}

Menopause is defined as the absence of menstrual cycles for 12 months, which occurs in women with average age of 51 years old. Vaginal bleeding, vaginal atrophy, hot flashes, mood changes, and fatigue are the symptoms of menopause. Fennel oil is used as treatment on menopausal women in clinical trials.

The effects of fennel oil oral capsule on menopause symptoms were the subject of placebo control double controlled clinical trial. The patients $(\mathrm{n}=90)$ with age of 45 to 60 years old, who were divided in two groups of placebo or fennel oil and received $100 \mathrm{mg}$ of fennel oil or sunflower oil, twice daily for 8 weeks. Menopause symptoms were evaluated by Menopause Rating Scale (MRS) questionnaire before and 8 weeks after interventions. A significant reduction in symptoms severity (hot flash, night sweating, heart disease, insomnia, and musculoskeletal disorders) were observed after 8 weeks of intervention by fennel oil compared with before intervention $(P<0.0001)$, and placebo group after intervention $(P<0.001){ }^{32}$ In randomized triple-blind clinical trial on 90 menopausal women, who received daily dose of $60 \mathrm{mg}$ fennel oil or placebo soft capsules (twice daily) for 8 weeks. The quality of life and different aspects of life were evaluated by MenopauseSpecific Quality of Life (MENQOL) questionnaire. Forty patients in each group of fennel or placebo groups completed the study without serious side effects during the study. The quality of life, vasomotor, physical, socio-psychological and sexual aspects significantly changed in fennel group, compared with placebo group. A significant improvement in quality of life and its four aspects were observed in the fennel group $(P<0.001)$ compared to placebo group. $^{33}$ In other double blind randomized placebo controlled study on 60 postmenopausal women, the efficacy of fennel was evaluated by Hospital Anxiety and Depression Scale (HADS) and Zung's Self-rating Depression Scale (SDS) compared to placebo. The patients received $30 \mathrm{mg}$ fennel oil or 
sunflower soft capsules every 8 hours for 4 weeks. Twentyfive and 24 participants completed the study in each group. There was no significant difference on the scores of SDS and HADS questionnaires after interventions $(P=0.91)$. The SDS scores decreased from $44.91 \pm 11.41$ to $41.96 \pm 10.07$ in fennel group $(P=0.07)$ and from $44.55 \pm 8.19$ to 42.27 $\pm 9.17(P=0.14)$ in placebo group. The only significant reduction was observed in fennel group in anxiety score of menopausal patients with depression and anxiety symptoms $(P<0.001){ }^{34}$ The oral administration of fennel oil $(\mathrm{n}=25)$ on menopausal symptoms in comparison with placebo $(\mathrm{n}=$ $25)$ showed that fennel oil improved the hot flush score $(P<0.001)$, night sweats $(P=0.007)$, sweating $(P=0.002)$, symptoms of anxiety $(P=0.05)$, feeling of depression $(P<$ $0.01)$, and impatience with the other people $(P<0.01)$ compared with before intervention. Hot flush score $(P<0.01)$, night sweats $(P<0.01)$, sweating $(P<0.01)$, anxiety symptoms $(P=0.001)$, feeling of depression $(P=0.006)$, and impatience with the other people $(P=0.003)$ improved in placebo groups. There was no significant difference between two groups in improvement of menopausal symptoms. ${ }^{35}$

There are two clinical studies which evaluates the efficacy of fennel oil on BMI and bone density in comparison with placebo. In first double-blind, randomized, placebo-controlled trial on overweight and obese menopausal women, who took $30 \mathrm{mg}$ fennel $(\mathrm{n}=25)$ or sunflower $(\mathrm{n}=22)$ soft capsules as placebo every 8 hours for 12 weeks. There was no significant difference in regard of menopause length, menopausal age, history of hysterectomy, number of children, body weight, level of educational, and other demographic status. A significant difference in BMI was observed at baseline. Five patients in the fennel group left the study due to allergic rash $(n=1)$, weight gain $(n=1)$, hypertension $(n=1)$, and vaginal bleeding $(n=2)$. Stomachache was reported in one patient of placebo group. No significant changes in body weight, BMI, waist and hip circumferences, and fat distribution were reported between placebo and fennel groups or in both groups before and after intervention. High compliances were reported in both groups. In spite of imbalance in BMI of two groups, fennel or placebo had no significant difference in BMI $(P=0.356){ }^{36}$ There was no significance between two group in regard of bone mineral density and bone mineral content of lumbar spine, total hip femoral, trochan- ter, intertrochanteric, and femoral neck. ${ }^{37}$ Therefore, fennel oil improves the clinical symptoms of menopause, but its effects are not better than placebo. It also has no effect on bone density and BMI of women during the post-menopausal period.

\section{Fennel oil and its effects on vaginal atrophy}

Atrophic vaginitis is associated with drying and inflammation of vaginal tissue due to deficient of estrogen after menopause. The vaginal atrophy is the main reason for painful intercourse. Due to estrogenic effects of fennel, its oil or extract can be a good choice in management of vaginal atrophy.

Fennel ethanol extract (5\%) in the form of vaginal cream (n = 30) was evaluated on vaginal $\mathrm{pH}$ and maturation vaginal index of post-menopausal women at baseline and after 2, 4, and 8 weeks of interventions, compared with placebo cream $(n=30)$. The results showed that fennel cream significantly increased the number of superficial vaginal cell after 8 weeks of treatment $(P<0.001)$, which associated with a significant reduction in the number of intermediate and para-basal cells in vagina compared to placebo group $(P<$ 0.001). Fennel cream reduced the vaginal $\mathrm{pH}$ in $100 \%$ cases, compared to $7.4 \%$ in placebo group $(P<0.001)$. The maturation index of 65 to 100 was observed in fennel group, while the maturation index of 50 to 64 was observed in $40.7 \%$ of patients in placebo group $(P<0.01)$. Fennel vaginal cream significantly improved itching, dryness, pallor, and dyspareunia $(P<0.05)$. Although, fennel vaginal cream improved the burning, but the difference was not significant $(P=0.14)$. There was no side effect during the study. ${ }^{38}$ Oral administration of $30 \mathrm{mg}$ fennel oil $(\mathrm{n}=27)$ or sunflower oil $(\mathrm{n}=25)$ every 8 hours for 8 weeks on vaginal atrophy of postmenopausal women had no significant effects on the number of para-basal $(P=0.191)$, superficial $(P=0.82)$ and intermediate $(P=0.291)$ cells, mature vaginal index $(P=0.64)$ and vaginal $\mathrm{pH}$. Five patients in fennel group experienced the side effects including frequent urination, rash, spotting. ${ }^{39}$ According to the results of two clinical studies, topical application of fennel extract improves the vaginal atrophy in postmenopausal women, while oral fennel oil had no effects on vaginal atrophy. Topical application of fennel oil was not the subject of any clinical trial, therefore, the efficacy of 
fennel extract and its oil in vaginal atrophy should be evaluated in further clinical studies.

\section{Fennel and its effects on sexual functions of menopausal women}

The estrogen and androgen deficiency in menopausal women reduce the blood flow in vulvovaginal region, which is the reason of libido and sexual arousal. Vaginal dryness reduces the sensory threshold of genital area, which causes dyspareunia and libido. Fennel ethanol extract vaginal cream ( $5 \mathrm{~g} /$ day) for 8 weeks $(\mathrm{n}=30)$, significantly increased the average of sexual satisfaction from $43.26 \pm 3.49$ to 73.16 $\pm 1.96(P<0.001)$. A significant reduction in painful intercourse was observed after intervention by fennel vaginal cream. The severity of dyspareunia significantly decreased in fennel group, compared to baseline $(P<0.001)$. At baseline of fennel group, $87.6 \%, 10 \%$, and $3.3 \%$ of patients in fennel group had severe, moderate, and mild dyspareunia, while at the end of intervention, $93.3 \%$ of subjects had no dyspareunia, followed by $6.7 \%$ mild one. The difference was significant between before and after intervention in fennel group $(P=0.001){ }^{40}$ In other randomized clinical trial, the efficacy of fennel ethanol extract vaginal cream was evaluated on sexual function of postmenopausal women $(\mathrm{n}=30)$ compared with placebo $(n=30)$. Female Sexual Function Index (FSFI) was evaluated at baseline and 8 weeks after the intervention. The patients took fennel vaginal cream (5 g) or placebo every night for 8 weeks. After 8 weeks of intervention by fennel and placebo cream, an improvement in arousal, lubrication, orgasm, sexual satisfaction and pain as sexual function were observed, but the difference of improvement was significant between two groups $(P<0.05)$. The total FSFI score was significantly increased in fennel group (8.2 \pm 9.4 to $33.79 \pm 0.7)$ compared to control group $(8.03 \pm 10.36$ to $18.99 \pm 1.09 ; P<0.001)$. No drop out was observed in groups, which introduce it as safe and acceptable treatment. ${ }^{41}$ As the results of two clinical trials showed, vaginal fennel ethanol extract cream could improve sexual functions in menopause women due to its estrogenic effects.

\section{Fennel and its effect on hirsutism}

The male pattern hair growth in women face or their body is defined as idiopathic hirsutism. The topical application of creams containing $1 \%(\mathrm{n}=11)$ and $2 \%(\mathrm{n}=15)$ of fennel ethanol extract compared with placebo cream $(n=12)$ for 12 weeks on 38 patients with idiopathic hirsutism in double blind placebo controlled study has been shown that the hair growth significantly reduced after fennel administration, which is associated with reduction in epilation frequency. The percent of hair reductions were $7.8 \%, 18.3 \%$, and $-0.5 \%$ for fennel creams $1 \%, 2 \%$, and placebo groups, respectively. A significant difference was observed between the efficacy of fennel extract $2 \%$ and $1 \%$ and each fennel group with placebo group. No adverse effects were reported for fennel creams. ${ }^{42}$ In randomized double blind placebo controlled clinical study, the anti-hirsutism effects of fennel ethanol extract gel (3\%) was compared with placebo cream on 44 women with mild to moderate idiopathic hirsutism. The thickness of facial hair was evaluated by microscope at baseline and after 24 weeks of treatment. The thickness of facial hair had 22.3 micron reduction after applying the fennel gel $(P<0.01)$. The difference in adverse effects was not significant between two groups. The thickness of facial hair changed from 92.1 \pm 29.5 to $97.0 \pm 29.6$ in control group and reduced from $97.9 \pm 31.5$ to $75.6 \pm 26.7$ in fennel group. ${ }^{43}$ The clinical studies on hirsutism had some limitation such as absence of standard for fennel fruit extract, no presence of severe hirsutism cases, and no follow up of the study. The estrogen compounds in fennel are able to inhibit the dihydrotestosterone synthesis in dermal papillae by inhibitory effect on $5-\alpha$-reductase or producing the weaker androgens from testosterone. Evaluating the efficacy of fennel oil in the forms of cream and gel in comparison with fennel extract formulations for management of hirsutism should be the title of future studies.

\section{Fennel and its effects on fertility}

Fennel consumption can improve the fertility according to traditional believes. The steroids and prolactin are involved in folliculogenesis. The estrogenic effects of oral fennel extract for 10 days on the weight of female genital organs (the mammary glands, oviduct, endometrium, myometrium, cervix, and vagina) have been shown. ${ }^{44}$ Fennel extract (100 and $200 \mathrm{mg} / \mathrm{kg}$ body weight) for 5 days increased significantly the number of total follicle (graffian, antral, and multilaminar follicles) in female albino rats, compared to 
placebo group $(P<0.05){ }^{45}$ Intra-peritoneal administration of fennel ethanol extract to virgin female mice for 5 days increased the level of estrogen, progesterone, dose dependently. ${ }^{46}$ The efficacy of fennel on endometrial thickness of 92 infertile women, who randomly divided into two groups of fennel tea $(n=45)$ and control $(n=47)$ groups. The patients of two groups took estradiol valerate $(2 \mathrm{mg})$ tablet every 8 hours from the third day of the menstrual cycle. Endometrial thickness was determined by ultrasound, serum $\beta$ human chorionic gonadotropin level and increase in estrogen dose. No significant differences were observed between two groups in regard of demographic characteristic $(P>0.05)$. The mean days to achieve endometrial thickness of at least $8 \mathrm{~mm}$ were $13.1 \pm 3.2$ and $14.2 \pm 3.5$ in fennel and control groups $(P>0.05){ }^{41}$ Although, fennel tea failed to achieve the adequate endometrial thickness for fertility, but evaluating the efficacy of fennel oil or extracts on fertility is recommended. The main reason for this recommendation is the use of standard and effective components with suitable doses in clinical trials.

\section{Fennel and its effects on amenorrhea}

Amenorrhea is the absence of menstrual periods as the result of problem in reproductive organs or hormone producing glands. Amenorrhea may be associated with milky nipple discharge, hair loss, hirsutism, pelvic pain, acne, and vision changes. The efficacy of fennel oil along with low dose of depot-medroxyprogesterone acetate (DMPA) as contraceptive tools on 78 married amenorrhea women was evaluated. The patients were randomly divided in three groups $(n=26)$ of low-dose combined oral contraceptive (LDL-COC) (30 $\mu \mathrm{g}$ ethinylestradiol and $150 \mu \mathrm{g}$ levonorgestrel) pills and fennel placebo, fennel and LDLCOC placebo and fennel placebo and LDL-COC for 21 days. The patients used one pills or capsules twice a day for 21 days or until the menstrual bleeding occurred. Seventy-three percentage of women in fennel group, and $81 \%$ in LDLCOC experienced menstrual bleeding, while menstrual bleeding was $19 \%$ in placebo group. The incidence of menstrual bleeding was not significant among two groups of LDL-COC and fennel groups. The mean amounts of menstrual bleeding were 21, 14, and $12 \mathrm{~mL}$ in fennel, LDL-COC and placebo groups, respectively. The subsequent DMPA injection were $73 \%, 65 \%$, and $31 \%$ in fennel, LDL-COC and placebo groups, respectively, which imply on positive effects of fennel and LDL-COC on resolving the amenorrhea. In regard of adverse effects, 8 women reported nausea (31\%), while $12 \%$ of patients in fennel group experienced heartburn. The adverse effects were tolerable. ${ }^{47}$ The results of one clinical trial confirmed the efficacy of daily $60 \mathrm{mg}$ fennel oil instead of synthetic estrogens in treatment of amenorrhea, with lower adverse effects.

\section{Fennel and its effects on lactation}

Prolactin is known as the hormone of lactation, which is produced by pituitary gland. The most important function of prolactin is stimulatory effects on milk production after delivery of baby. High level of prolactin during pregnancy enlarges mammary glands and milk release in women's breast for breastfeeding. High level of prolactin during the first several months of breast feeding inhibits ovulation. The inductive role of fennel on prolactin production has been confirmed in preclinical and clinical studies. Intra-peritoneal administration of fennel aqueous extract for 5 and 10 days significantly increased the serum prolactin. ${ }^{48}$ Furthermore, intra-peritoneal administration of 100 and $200 \mathrm{mg} / \mathrm{kg}$ fennel ethanol extract to virgin female mice for 5 days increased the level of prolactin, dose dependently. ${ }^{46}$ Fennel seed (6 capsule $500 \mathrm{mg}$, three times in a day) increased serum prolactin from $64.55 \pm 32.06$ to $95.55 \pm 65.9$ after treatment with fennel seed $(P<0.001)$ in lactating women $(\mathrm{n}=46)^{49}$ Fennel oil or extract is suitable lactating agent for women in nursing period, but the use of fennel in pregnant or breast feeding mothers is not recommended by Committee on Herbal Medicinal Products (HMPC) of European Medicines Agency due to insufficient data.

\section{Fennel and polycystic ovary syndrome (PCOS)}

PCOS is associated with oligomenorrhea or amenorrhea and is identified by absence of ovulation and hyperandrogenism. Fennel due to phytoestrogen compounds and according to traditional believes has the potential for management of polycystic ovary (PCO) treatment. Fennel extract reduced the serum estrogen level and thickness of uterine epithelial cells and increased the serum progesterone level and endometrial thickness of PCOS mice. ${ }^{50}$ Intra-peritoneal injection of estradiol valerate treated rats with fennel hydro 
alcoholic acid (250, 500, and 1,000 mg/kg) for 10 days increased the serum follicle-stimulating hormone (FSH) concentration and decreased serum $\mathrm{LH}$ and testosterone in dose dependent manner. Estradiol valerate induced PCO in rats by increasing the $\mathrm{LH}$ and testosterone level and decreasing the FSH level. ${ }^{51}$ The results of preclinical studies were confirmed by clinical trial on subjects, $92 \mathrm{mg}$ daily fennel ( $\mathrm{n}$ $=15$ ) capsule, for 90 days had no effect on serum levels of thyroid stimulating hormone $(P=0.298)$, luteinizing hormone $(P=0.178)$, and dehydroepiandrosterone sulfate $(P=$ 0.641), while serum follicle-stimulating hormone $(P=0.021)$ level showed significance difference with placebo group. ${ }^{52}$ The reason for the low efficacy of fennel is the low dose of extract or the low number of patients under study, also the efficacy of fennel oil on PCOS patients should be the subject of larger clinical trials.

\section{Toxicology}

The oral lethal dose $50\left(\mathrm{LD}_{50}\right)$ for fennel oil in rats were $1,326 \mathrm{mg} / \mathrm{kg}$, which is classified as slight toxic substances. The toxic effects of fennel oil are as the result of metabolite imbalance or nervous cytotoxicity. ${ }^{30}$ Intra-peritoneal fennel aqueous extract $(400-6,400 \mathrm{mg} / \mathrm{kg}$ ) had no toxic effect in mice. ${ }^{31}$ The oral $\mathrm{LD}_{50}$ for fennel aerial parts oil is reported higher than $2,000 \mathrm{mg} / \mathrm{kg}$ in mice. ${ }^{13}$ Fennel fruits have estrogenic effects, which puberty appears in girls sooner. Therefore the use of fennel is not recommended during pregnancy. ${ }^{53}$ Fennel is one of plant, which is used during the pregnancy with frequency of $10.3 \%$. One case of constipation was reported after regular consumption of decoction containing fennel with a mix of herb. ${ }^{54}$ Oral fennel administration for entire period of pregnancy is associated with shorter gestational age. ${ }^{55}$ Fennel reduces the limb bud differentiation from day 13 rat embryo, which is associated with cell loss, no cell differentiation, implying toxic effects of fennel oil on fetal cells, without any evidence of tetragenicity. ${ }^{56}$ The inhibitory effects of fennel methanol extract on human liver cytochrome P4503A4, exhibited the potential interaction of fennel with drugs. ${ }^{7}$ Premature thelarche is described in prepubertal girl, who consumed fennel tea and had breast development. $^{57}$

\section{Conclusion}

The review article summarized the potency of fennel on different gynecological disorders including premenstrual disorders, dysmenorrhea, menopause, amenorrhea, lactation and PCOS. The majority articles evaluated the efficacy of fennel essential oil at dose of $30 \mathrm{mg}$ (15-30 drops), two or three times in a day, but fennel ethanol extract at concentration of $46 \mathrm{mg}$ every 6 hours has been used in some studies. What is certain, the efficacy of fennel oil is higher than its extract, although, fennel ethanol extract 5\% has good efficacy in treatment of vaginal atrophy. Furthermore, fennel tea (5 g dried fruit in $130 \mathrm{~mL}$ boiled water) with well tolerability reduced the time to first flatus and defecation, length of parenteral nutrition, postoperative hospital stay, ileus symptoms of postoperative gut recovery of women undergoing gynecological malignancies operation. ${ }^{58}$ Lactating effects of fennel on women along with the curative effects on infantile colic ${ }^{29,59,60}$ make it as popular herbal plant after delivery of baby. Thirty milligrams of fennel oil capsule ( $\mathrm{n}=$ 43) had been superior to mefenamic acid $(n=43)$ in reduction of pain after giving birth without abnormal bleeding or adverse effects during the intervention. ${ }^{61}$ The beneficial effects of fennel oil or extracts in gynecological problems of women are related to its phytoestrogen compounds such as diosgenin. Progesterone as a steroid hormone along with estrogen has supportive care in body. ${ }^{46,62}$ Its analgesic effects and anti-spasmolytic effects along with its estrogenic effects make it as suitable treatment for management of gynecological disorders. The huge number of studies on fennel is focused on its essential oil, although its extract has been used topically or orally in clinical trials, but designing the large clinical trials in order to compare the efficacy of fennel extract with oil should be considered. Although the efficacy of fennel oil has been evaluated on hirsutism, fertility and PCOS, but the limited number of participants or the unsuitable dose of fennel makes the conclusion difficult on its efficacy. So, large clinical trials for evaluating its efficacy in fertility, PCOS, hirsutism could be the subjects of studies in future. 


\section{Conflict of Interest}

No potential conflict of interest relevant to this article was reported.

\section{References}

1. Aghili MH. [Drug reservoir]. Tehran, Iran: Tehran University of Medical Sciences; 2009. Persian.

2. Razi M. [Content in medicine]. Beirut, Lebanon: Dar Al Kotob Al-ilmiyah; 2000. Arabic.

3. Ibn Sina. [Canon in medicine (Arabic)]. Sharafkandi A, translator. Tehran, Iran: Soroush Press; 2005. Perisian.

4. Tonkaboni MM. [Gift of believers]. Tehran, Iran: Shahid Beheshti University of Medical Sciences; 2007. Persian.

5. Rahimi R, Ardekani MR. Medicinal properties of Foeniculum vulgare Mill. In traditional Iranian medicine and modern phytotherapy. Chin J Integr Med 2013; 19: 73-9.

6. Amini F, Marzban M, Salehi A. The effect of Foeniculum vulgare on dysmenorrhea; a systematic review. Planta Med 2016; 82(Suppl 1): S1-S381.

7. Badgujar SB, Patel VV, Bandivdekar AH. Foeniculum vulgare Mill: a review of its botany, phytochemistry, pharmacology, contemporary application, and toxicology. Biomed Res Int 2014; 2014: 842674.

8. Nazarpour S, Azimi H. Comparison of therapeutic effects of fennelin and mefenamic acid on primary dysmenorrhea. J Mazandaran Univ Med Sci 2007; 17: 54-61.

9. Delaram M, Jafari F. The effect of fennel on the pre-menstrual syndrome. Knowl Health 2011; 6: 1-6.

10. Omidali F. The effect of Pilates exercise and consuming Fennel on pre-menstrual syndrome symptoms in non-athletic girls. Complement Med J Fac Nurs Midwifery 2015; 5: 120313.

11. Pazoki H, Bolouri G, Farokhi F, Azerbayjani MA. Comparing the effects of aerobic exercise and Foeniculum vulgare on pre-menstrual syndrome. Middle East Fertil Soc J 2016; 21: 614 .

12. Pourabbas S, Kesmati M, Rasekh A. Study of the the anxiolytic effects of fennel and possible roles of both gabaergic system and estrogen receptors in these effects in adult female rat. Physiol Pharmacol 2001; 15: 134-43.

13. Mesfin M, Asres K, Shibeshi W. Evaluation of anxiolytic activity of the essential oil of the aerial part of Foeniculum vulgare Miller in mice. BMC Complement Altern Med 2014; 14: 310 .

14. Khorshidi N, Ostad SN, Mosaddegh M, Soodi M. Clini- cal effects of fennel essential oil on primary dysmenorrhea. Iran J Pharm Res 2003; 2: 89-93.

15. Akhavan Amjadi M, Zahrani S, Mojab F, Alavi Majd H. Efficacy of Foeniculum vulgare Mill extract on menstrual bleeding over the students of Shahid Beheshti University in Tehran 2005. J Med Plant 2010; 2: 117-23.

16. Bokaie M, Farajkhoda T, Enjezab B, Khoshbin A, KarimiZarchi M. Oral fennel (Foeniculum vulgare) drop effect on primary dysmenorrhea: effectiveness of herbal drug. Iran $\mathrm{J}$ Nurs Midwifery Res 2013; 18: 12832.

17. Bokaie M, Enjezab B. The effects of oral fennel extract on the intensity of menstrual bleeding in relieving dysmenorrheal: a randomized clinical trial. Community Health $\mathrm{J}$ 2014; 8: 55-62.

18. Ghodsi Z, Asltoghiri M. The effect of fennel on pain quality, symptoms, and menstrual duration in primary dysmenorrhea. J Pediatr Adolesc Gynecol 2014; 27: 283-6.

19. Abdollahi NG, Mirghafourvand M, Mollazadeh S. The effects of fennel on menstrual bleeding: a systematic review and meta-analysis. J Complement Integr Med 2018; 15. doi: 10.1515/jcim-2017-0154.

20. Namavar Jahromi B, Tartifizadeh A, Khabnadideh S. Comparison of fennel and mefenamic acid for the treatment of primary dysmenorrhea. Int J Gynaecol Obstet 2003; 80: 153-7.

21. Yazdani M, Shahriari M, Hamedi B. Comparison of fennel and chamomile extract and placebo in treatment of premenstrual syndrome and dysmenorrheal. Med J Hormozgan Univ 2004; 8: 57-61.

22. Modaress Nejad V, Motamedi B, Asadi pour M. Comparison between the pain-relief effect of fennel and mefenamic acid on primary dysmenorrhea. J Rafsanjan Univ Med Sci 2006; 5: $1-6$.

23. Torkzahrai S, Akhavan-Amjadi M, Mojab F, Alavimajd $\mathrm{H}$. Clinical effects of Foeniculum vulgare extract on primary dysmenorrhea. J Product Infertil 2007; 8: 45-51.

24. Delaram M, Forouzandeh N. The effect of Fennel on the primary dysmenorrhea in students of Shahrekord University of Medical Sciences. Jundishapur Sci Med J 2011; 10: 81-8.

25. Moslemi L, Aghamohammadi A, Bekhradi R, Zafari M. Comparing the effects of vitamin $\mathrm{E}$ and fennel extract on intensity of primary dysmenorrhea. J Mazandaran Univ Med Sci 2012; 22: 103-7.

26. Omidvar S, Esmailzadeh S, Baradaran M, Basirat Z. Effect of fennel on pain intensity in dysmenorrhoea: a placebocontrolled trial. Ayu 2012; 33: 311-3.

27. Moslemi l, Bekheradi R, Hasani S, Khaleghinezhad K. The effect of fennel oil on primary dysmenorrhea. Fam Health 2013; 1: 15-20. 
28. Zeraati F, Shobeiri F, Nazari M, Araghchian M, Bekhradi R. Comparative evaluation of the efficacy of herbal drugs (fennelin and vitagnus) and mefenamic acid in the treatment of primary dysmenorrhea. Iran J Nurs Midwifery Res 2014; 19: $581-4$.

29. Alexandrovich I, Rakovitskaya O, Kolmo E, Sidorova T, Shushunov S. The effect of fennel (Foeniculum Vulgare) seed oil emulsion in infantile colic: a randomized, placebocontrolled study. Altern Ther Health Med 2003; 9: 58-61.

30. Ostad SN, Soodi M, Shariffzadeh M, Khorshidi N, Marzban

$H$. The effect of fennel essential oil on uterine contraction as a model for dysmenorrhea, pharmacology and toxicology study. J Ethnopharmacol 2001; 76: 299-304.

31. Zendehdel M, Taati M, Amoozad M, Hamidi F. Antinociceptive effect of the aqueous extract obtained from Foeniculum vulgare in mice: the role of histamine $\mathrm{H} 1$ and $\mathrm{H} 2$ receptors. Iran J Vet Res 2012; 13: 100-6.

32. Rahimikian F, Rahimi R, Golzareh P, Bekhradi R, Mehran A. Effect of Foeniculum vulgare Mill. (fennel) on menopausal symptoms in postmenopausal women: a randomized, tripleblind, placebo-controlled trial. Menopause 2017; 24: 1017-21.

33. Kian FR, Bekhradi R, Rahimi R, Golzareh P, Mehran A. Evaluating the effect of fennel soft capsules on the quality of life and its different aspects in menopausal women: a randomized clinical trial. Nurs Pract Today 2017; 4: 87-95.

34. Ghazanfarpour M, Mohammadzadeh F, Shokrollahi P, Khadivzadeh T, Najaf Najafi M, Hajirezaee H, et al. Effect of Foeniculum vulgare (fennel) on symptoms of depression and anxiety in postmenopausal women: a double-blind randomised controlled trial. J Obstet Gynaecol 2018; 38: 121-6.

35. Ghazanfarpour M, Najafi MN, Sharghi NB, Mousavi MS, Babakhanian M, Rakhshanded H. A double-blind, placebocontrolled trial of Fennel (Foeniculum vulgare) on menopausal symptoms: a high placebo response. J Turk Ger Gynecol Assoc 2018; 19: 122-7.

36. Saghafi N, Ghazanfarpour M, Khadivzadeh T, Babakhanian M, Afiat M. The effect of Foeniculum vulgare (fennel) on body composition in postmenopausal women with excess weight: a double-blind randomized placebo-controlled trial. J Menopausal Med 2017; 23: 166-71.

37. Ghazanfarpour M, Amini E, Khadivzadeh T, Babakhanian M, Nouri B, Rakhshandeh H, et al. The effect of short-term treatment with fennel on bone density in postmenopausal women: a randomized controlled trial. J Menopausal Med 2017; 23: 124-30.

38. Yaralizadeh M, Abedi P, Najar S, Namjoyan F, Saki A. Effect of Foeniculum vulgare (fennel) vaginal cream on vaginal atrophy in postmenopausal women: a double-blind randomized placebo-controlled trial. Maturitas 2016; 84: 75-
80.

39. Ghazanfarpour M, Shokrollahi P, Khadivzadeh T, Baharian Sharghi N, Mirzaii Najmabadi K, Babakhanian M, et al. Effect of Foeniculum vulgare (fennel) on vaginal atrophy in postmenopausal women: a double-blind, randomized, placebo-controlled trial. Post Reprod Health 2017; 23: 171-6.

40. Najar S, Yaralizadeh M, Abedi P, Namjooyan F, Malehi O. Effect of fennel vaginal cream on dysparonia and sexual satisfaction among postmenopausal women: a double-blind randomized controlled trial. Iran J Obstet Gynecol Infertil 2015; 18: 8-16.

41. Yavangi M, Rabiee S, Nazari S, Farimani-Sanoee M, Amiri I, Bahmanzadeh $\mathrm{M}$, et al. Comparison of the effect of oestrogen plus foeniculum vulgare seed and oestrogen alone on increase in endometrial thickness in infertile women. J Clin Diagn Res 2018; 12: QC014.

42. Javidnia K, Dastgheib L, Mohammadi Samani S, Nasiri A. Antihirsutism activity of Fennel (fruits of Foeniculum vulgare) extract. A double-blind placebo controlled study. Phytomedicine 2003; 10: 455-8.

43. Akha O, Rabiei K, Kashi Z, Bahar A, Zaeif-Khorasani E, Kosaryan M, et al. The effect of fennel (Foeniculum vulgare) gel 3\% in decreasing hair thickness in idiopathic mild to moderate hirsutism, a randomized placebo controlled clinical trial. Caspian J Intern Med 2014; 5: 26-9.

44. Malini T, Vanithakumari G, Megala N, Anusya S, Devi K, Elango V. Effect of Foeniculum vulgare Mill. seed extract on the genital organs of male and female rats. Indian $\mathrm{J}$ Physiol Pharmacol 1985; 29: 21-6.

45. Khazaei M, Montaseri A, Khazaei MR, Khanahmadi M. Study of Foeniculum vulgare effect on folliculogenesis in female mice. Int J Fertil Steril 2011; 5: 122-7.

46. Sadeghpour N, Khaki AA, Najafpour A, Dolatkhah H, Montaseri A. Study of Foeniculum vulgare (fennel) seed extract effects on serum level of estrogen, progesterone and prolactin in mouse. Crescent J Med Biol Sci 2015; 2: 59-63.

47. Mohebbi-Kian E, Mohammad-Alizadeh-Charandabi S, Bekhradi R. Efficacy of fennel and combined oral contraceptive on depot medroxyprogesterone acetate-induced amenorrhea: a randomized placebo-controlled trial. Contraception 2014; 90: 440-6.

48. Siahi M, Shirovi A, Heidari Nasrabadi M. Effect of fennel aqueous extract on the level of prolactin in female Wistar rat. J Zool Biol 2009; 1: 55-63.

49. Honarvar F, Tadayon M, Afshari P, Namjooyan F, Haghighi $\mathrm{MH}$. The effect of Foeniculum vulgare on serum prolactin level in lactating women. Iran J Obstet Gynecol Infertil 2013; 16: 18-24.

50. Sadr Fozalaee S, Farokhi F, Khaneshi F. The effect of 
metformin and aqueous extract Foeniculumvulgare (fennel) on endometrial histomorphometry and the level of steroid hormones in rats with polycystic ovary syndrome. Qom Univ Med Sci J 2015; 8: 12-9.

51. Karampoor P, Azarnia M, Mirabolghasemi G, Alizadeh F. The effect of hydroalcoholic extract of fennel (Foeniculum vulgare) seed on serum levels of sexual hormones in female Wistar rats with polycystic ovarian syndrome (PCOS). J Arak Uni Med Sci 2014; 17: 70-8.

52. Ghavi F, Shakeri F. Effects of fennel on serum hormone levels in students with polycystic ovary syndrome. Avicenna J Phytomed 2015; 5: 42-3.

53. Forster HB, Niklas H, Lutz S. Antispasmodic effects of some medicinal plants. Planta Med 1980; 40: 309-19.

54. Facchinetti F, Pedrielli G, Benoni G, Joppi M, Verlato G, Dante G, et al. Herbal supplements in pregnancy: unexpected results from a multicentre study. Hum Reprod 2012; 27: 3161-7.

55. Trabace L, Tucci P, Ciuffreda L, Matteo M, Fortunato F, Campolongo $\mathrm{P}$, et al. "Natural" relief of pregnancy-related symptoms and neonatal outcomes: above all do no harm. J Ethnopharmacol 2015; 174: 396-402.
56. Ostad SN, Khakinegad B, Sabzevari O. Evaluation of the teratogenicity of fennel essential oil (FEO) on the rat embryo limb buds culture. Toxicol In Vitro 2004; 18: 623-7.

57. Okdemir D, Hatipoglu N, Kurtoglu S, Akın L, Kendirci M. Premature thelarche related to fennel tea consumption? J Pediatr Endocrinol Metab 2014; 27: 175-9.

58. Ma HW, Zhao JT, Zhao X. [The effect of fennel tea drinking on postoperative gut recovery after gynecological malignancies operation]. Sichuan Da Xue Xue Bao Yi Xue Ban 2015; 46: 940-3. Chinese.

59. Page JG, Dirnberger GM. Treatment of the irritable bowel syndrome with Bentyl (dicyclomine hydrochloride). J Clin Gastroenterol 1981; 3: 153-6.

60. Attarha M, Rosbahani N, Youssefi P. Comparison of the effect of fennel essence and gripe water syrup in infantile colic. Sci J Kurd Univ Med Sci 2008; 13: 28-35.

61. Golian Tehrani S, Mirmohammadali M, Soltani Moghadam A, Mehran A, Taghi Zadea M, Baleghi M. The comparison of fennel and mefenamic acid effects on post-partum after pain. J Babol Univ Med Sci 2015; 17: 7-13.

62. Kumar P, Magon N. Hormones in pregnancy. Niger Med J 2012; 53: 179-83. 